\title{
ENTREVISTA COM LUCA BUSSOTTI: OS MOVIMENTOS SOCIAIS ALTERNATIVOS EM MOÇAMBIQUE
}

INTERVIEW WITH LUCA BUSSOTTI: ALTERNATIVE SOCIAL MOVEMENTS IN MOZAMBIQUE

Jaqueline Barbosa da Silva ${ }^{1}$

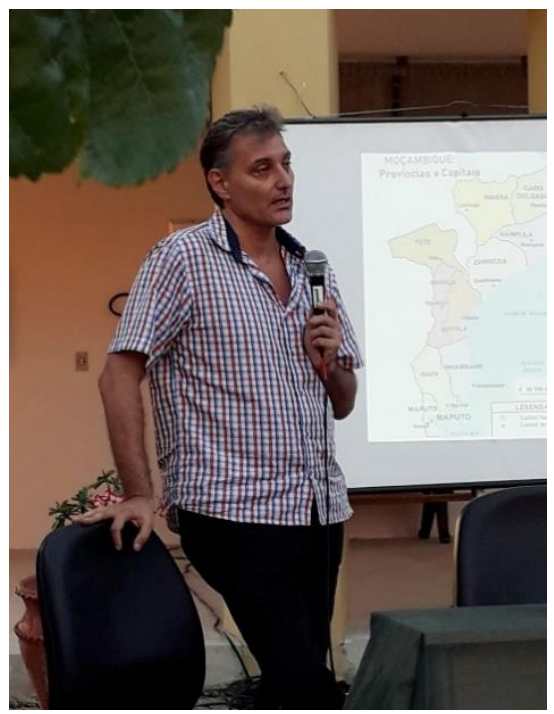

Luca Bussotti em Conferência Fonte: Acervo da entrevistadora

\section{APRESENTAÇÃO}

Luca Bussotti é Professor Associado Visitante da Universidade Federal de Pernambuco, no Programa de Pós-Graduação em Sociologia e Afeto ao Instituto de Estudos Africanos (IEAF) da mesma Universidade. Possui doutorado - Universitá di Pisa (2001), e pós-doutorado

\footnotetext{
${ }^{1}$ Doutora e Mestre em Educação pela Universidade Federal de Pernambuco (UFPE). Licenciada em Pedagogia pela UFPE. Atualmente é professora do Núcleo de Formação Docente, do Campus Agreste da UFPE, onde exerce a docência, a extensão e a pesquisa. Tem experiência na área de Educação, com ênfase em política educacional e formação de professores, atuando principalmente nos seguintes temas: Educação do Campo, Prática Educativa, Educação Popular, Movimentos Sociais e Pesquisa (Auto)Biográfica. E-mail: jaqueline.barbosa @ yahoo.com.br
} 
pelo Centro de Estudos Internacionais do ISCTE-IUL (Lisboa). Até final de 2018 foi Diretor da Pós-Graduação da Universidade Técnica de Moçambique (UDM) e Coordenador do Curso de Doutorado em Paz, Democracia, Movimentos Sociais e Desenvolvimento Económico da mesma UDM (Maputo-Moçambique). É investigador Sénior no CEC (Maputo-Moçambique), Professor Convidado pela Faculdade de Direito e pela Faculdade de Ciências Sociais, Programas de Pós-Graduação da Universidade Eduardo Mondlane (Maputo-Moçambique), Diretor da coleção de livros Lusitánica (Turim, L'Harmattan Italia), Investigador no Centro de Estudos Internacionais do ISCTE-IUL, Lisboa. Tem experiência na área de Sociologia, com ênfase em Sociologia do Desenvolvimento, nos Estudos Africanos e nos Estudos Interculturais. Seus estudos oferecem importantes recursos teóricos e conceituais para compreender a sociologia do desenvolvimento, o legado africano e a interculturalidade; para maiores informações acessar o currículo lattes ${ }^{2}$. A entrevista que segue foi motivada pela participação no VI Seminário Integrado, promovido pelo curso de licenciatura em Pedagogia, do Campus Agreste, da Universidade Federal de Pernambuco, no dia 07 de novembro de 2019, no qual proferiu a conferência de encerramento intitulada: Os Movimentos Sociais alternativos em Moçambique.

Jaqueline Barbosa da Silva (JBS): Como se deu a evolução dos movimentos sociais na África e, especificamente, em Moçambique?

Luca Bussotti (LB): Primeiro é preciso perceber o que é que a gente entende com a expressão de "movimentos sociais". Muitos sociólogos de renome, desde Touraine até Tarrow, desde Melucci até Castells abordam este assunto, com suas diferentes caraterísticas e evoluções. Entretanto, tais abordagens dizem respeito ao contexto ocidental, em que a formação dos movimentos sociais foi endógena, por exemplo como no caso do movimento estudantil de 1968 ou dos movimentos ecologistas e pacifistas dos anos 1970 e 1980. Em África o contexto é

\footnotetext{
${ }^{2}$ Versão completa disponibilizada em: <http://lattes.cnpq.br/8659437222936712>. Acesso em 17 de novembro de 2019.
} 
diferente. Podemos afirmar que os primeiros movimentos sociais se deram, neste continente, em contraposição à colonialidade. Quando uso esta palavra, ela deve ser interpretada muito mais como um processo e uma condição humana tout court de submissão às metrópoles ocidentais e à sua cultura do que como o simples fato de ausência de independência política. A oposição à colonialidade resultou em movimentos, primeiro de tipo filosófico e literário, e logo a seguir político. No caso de Moçambique se formaram vários movimentos nacionalistas, que confluíram na FRELIMO ${ }^{3}$ em 1962, e que depois (em alguns casos) se dissociaram da mesma FRELIMO (tais como Coremo e Gumo), embora, esta parte da história tenha sido largamente negligenciada. Logo após a independência, em 1975, a RENAMO 4 pode ser considerada como movimento social (não interessa muito, aqui, se totalmente endógeno ou em prevalência exógeno) de oposição a uma FRELIMO que, no entretanto, se tinha tornado partido-Estado, institucionalizando-se. Tais processos caracterizam boa parte dos países africanos, pelo menos os muitos que passaram por uma experiência de regimes de partido único. Porém, movimentos sociais mais modernos, no contexto africano, surgiram mais tarde, nos anos 1990, depois da vaga de liberalizações políticas e econômicas. Foi por isso que, o primeiro estudo sistemático em volta deste assunto só saiu em 1995, cujos autores, Mamdami e Wamba-dia-Wamba, denunciavam justamente o desinteresse da literatura especializada para com os movimentos sociais africanos. O outro estudo, que marcou a investigação sobre movimentos sociais em África, foi o de Ellis e Van Kessel, publicado em 2009, com uma abordagem indutiva, evitando fornecer a priori uma definição de movimentos sociais. Assim, no contexto africano os movimentos sociais dignos deste nome (não considero tais as várias OSC financiadas por Estados africanos ou doadores internacionais) se deram ainda muito mais tarde, pois era necessário ter uma agenda própria, com uma pauta bem definida e clara. Primeiro tais movimentos atuaram no meio urbano, por exemplo assumindo a agenda dos direitos (humanos, das mulheres, etc.) como própria e como instrumento para limitar os abusos dos respetivos Estados que, de revolucionários, se tinham transformado em autoritários. O caso de Moçambique é, infelizmente, um ótimo exemplo disso. Depois houve movimentos sociais mais

\footnotetext{
${ }^{3}$ Frente de Libertação em Moçambique

${ }^{4}$ Resistência Nacional Moçambicana
} 
parecidos com movimentos de puro protesto, ligados mais a situações contingentes do que a uma ideia estruturada de mudança social. Em Moçambique, os tumultos de 2008 e 2010 em Maputo aludem a um tal cenário (não menciono, aqui, a Primavera Árabe, pois está um pouco longe do contexto da África subsaariana a que me refiro). Mas, a partir aproximadamente de 2009 e 2010, a grande força de movimentos sociais maduros, mesmo do ponto de vista ideológico, se concentrou, na minha opinião, no meio rural. Programas de grande vulto, tais como o Pro-Savana em Moçambique, supostamente pensado para "valorizar" 11 milhões de hectares de terra no Norte do país, mas em verdade querendo usurpar tal terra aos camponeses, para torná-los simples assalariados de empresas viradas à produção de commodities para exportação, desencadearam a reação de comunidades, auxiliadas por novas OSC que conseguiram se juntar por uma causa comum: a terra. O movimento do "Não ao Pro-Savana" procurou fazer isso, com resultados bons (o programa foi de fato suspenso, apesar da insistência da JICA, a Cooperação japonesa e, em parte, da ABC), assim como a ação das comunidades de Manica e Zambézia e de OSC, tais como ADECRU e Justiça Ambiental conseguiram pelo menos diminuir as pretensões de empresas como a Portucel ao nível da silvicultura. Os movimentos sociais africanos, hoje, lutam basicamente para fazer face a este conluio terrível entre multinacionais ocidentais ou asiáticas e elites políticas locais, num contexto de alta corrupção e de restringimento dos espaços democráticos, em Moçambique assim como em muitos outros países.

\section{JBS: Ao comparar os movimentos sociais da África e do Brasil, é possível identificar semelhanças? Há algum limite quando nos remetemos a uma agenda contemporânea de afirmação étnico-político-social em defesa da diversidade epistêmica?}

LB: Sim, existem semelhanças, assim como existem alianças, por exemplo, expressas através da rede do Movimento Sem Terra. As semelhanças se prendem pelo fato de os processos que determinam grandes usurpações de terra (ou outras violações dos direitos humanos igualmente graves) responderem à mesma pauta: produzir commodities para exportação, sobretudo para 
mercados asiáticos. O modelo de desenvolvimento a que este processo alude é completamente extravertido, usando as palavras de Samir Amin e dos teóricos da dependência, tão que voltando ao exemplo anterior - o programa Pro-Savana se inspira à experiência brasileira do Prodecer. Tais processos econômicos tem outro elemento comum: ignorar ou até anular os saberes locais, considerados inúteis no panorama de uma periferização de boa parte do mundo (sobretudo no hemisfério Sul), em prol das elites ocidentais. As quais - nunca podemos esquecer disto - encontram em muitos países africanos os seus grandes aliados nas classes políticas locais. Este elemento de análise, muitas vezes é negligenciado, sobretudo na América Latina e mesma na Europa: seria bem difícil a afirmação deste mega-processo de periferização global sem que as classes políticas africanas aceitassem uma tal aliança. O neoliberalismo, portanto, representa sim o cenário comum a estes fenômenos nos vários cantos do mundo, mas também não pode ser considerado como justificação para explicar os deploráveis comportamentos de uma classe de indivíduos com responsabilidades públicas, mas que na verdade utiliza seus cargos para fins exclusivamente pessoais, em detrimento das populações locais. O filósofo moçambicano Severino Ngoenha tem falado, nos seus livros (inclusive no último, Lomuko, sobre a sociedade civil) de "dólar-cracia” que já há muito tempo se apoderou das práticas políticas dos governantes daquele país (assim como de muitos outros). A grande diferença que eu vejo entre movimentos sociais africanos e os brasileiros é que estes últimos, geralmente, conseguem ter uma frente vasta de solidariedade na arena política ou, por vezes, por exemplo, na altura dos governos de Lula e Dilma, institucional. O que em África raras vezes acontece, deixando, portanto, tais movimentos sociais mais isolados e fracos diante dos processos de periferização global.

JBS: A concepção genuína da teoria cultural para a formação dos movimentos sociais, sistematizada por Melluci (1988), explica a conversão de cidadãos comuns em ativistas por meio de um processo que envolve simultaneamente racionalidade e emoção. Pergunto: seriam os novos movimentos sociais uma forma outra de manipulação emanados por uma mobilização que almeja mudanças culturais voltada à sociedade civil e não mais ao 
Estado? Se assim o for, explica-se o uso do advérbio "novo" para distingui-los dos "velhos"? Nessa distinção entre "novo" e "velho", qual o lugar dos "alternativos" relacionado aos movimentos sociais?

LB: Em boa verdade, os movimentos sociais deveriam trazer, como seu elemento ontológico, o fato de serem "alternativos". Os movimentos de libertação africanos dos anos 1950 e 1960 (para as antigas colônias portuguesas até os anos 1970) o foram, embora acredito que a sua força revolucionária parou aquando da escolha do Estado nacional (com as fronteiras coloniais) como forma única de governação do continente. A partir daí, os movimentos sociais mais vivos surgiram em contraposição aos Estados nacionais, independentemente da matriz ideológica de cada um deles. Mesmo no novo quadro em que se deu, a partir dos anos noventa (com a abertura de muitos países africanos para o liberalismo e o pluralismo político), é duvidoso se os movimentos sociais que se desenvolveram adquiriram a maturidade de apresentarem-se como "alternativos". Existem, por exemplo, movimentos sociais "egoístas" (não necessariamente num sentido depreciativo), ou seja, que respondem a uma pauta imediata, visando solucionar um problema causado geralmente por um fator externo. Os reassentamentos (quase sempre mal feitos), em seguida a um investimento por parte de uma empresa privada, constituem o caso mais comum. Em Moçambique, a brasileira Vale, com um empreendimento na área do carvão em Tete, que foi considerado por muitos observadores como paradigma negativo de afastamento de uma população do seu local de vida e trabalho, provocou o surgimento de um forte movimento social de protesto. Tal movimento foi "egoísta" e "imediatista", liderado por um grupo de oleiros, visando solucionar o problema contingente de indenizações julgadas insuficientes por parte da Vale. Nestes protestos não havia nenhuma outra perspectiva, a não ser obter mais dinheiro da Vale, nenhuma ideia de juntar o movimento com outros que estivessem passando por situações parecidas, tão que, uma vez conseguido o resultado almejado, o movimento cessou. Os exemplos do Não ao Pro-Savana ou da rede de camponeses em luta contra a silvicultura no Centro de Moçambique são, pelo contrário, verdadeiros movimentos "alternativos", pois eles têm uma pauta acima de tudo material (conservar as suas terras para o próprio sustento), visando resolver um problema específico e local, mas 
compreendendo que não é possível fazer isso sem alargar o seu olhar para situações similares. Daqui, os encontros de formação e troca mútua sobre a lei da terra, os direitos das comunidades (além de que dos indivíduos) no meio rural, das mulheres camponesas, a valorização das culturas locais como meio de identidade e de luta para resistir à pressão finalizada à periferização global desta parte do planeta, procurando naqueles saberes e naquelas trocas novas formas de uso da terra e de convivência sustentável, quer do ponto de vista ambiental, quer social. Em suma, algo muito próximo ao que a Escola de Coimbra, liderada por Boaventura de Sousa Santos e Paula Meneses, definem de recuperação das epistemologias do Sul: uma recuperação que ocorre desde o baixo, partindo de problemas concretos e pensando numa forma solidária para com quem está atravessando os mesmos constrangimentos, indo além do "egoísmo imediatista" que vimos no caso dos oleiros de Tete. Do meu ponto de vista, muito mais do que do cenário político, possíveis mudanças, em África e em Moçambique, poderão vir destes movimentos sociais, que representam os elementos novos num contexto cristalizado, pelo menos em Moçambique (mas também em outros países da África Austral, tais como Angola, África do Sul e outros).

JBS: Nas últimas décadas temos presenciado várias críticas ao modo de fazer Ciência no Ensino Superior, entre elas encontram-se os limites da universidade moderna e ocidental no trato com a diversidade epistêmica e a transculturalidade. Por exemplo, o estudo em volta dos movimentos sociais e dos saberes locais é relativamente recente, e nem sempre constitui o assunto principal a ser investigado. Como você avalia essas críticas?

LB: O ensino superior deveria ter uma grande responsabilidade: levar adiante tais críticas ao modelo dominante e aos processos de periferização global. Infelizmente, isto nem sempre acontece, ainda menos no contexto africano, onde as limitações à liberdade de expressão sobretudo quando as críticas são dirigidas à elite no poder - representam uma constante. Este é um dos motivos que faz com que a maioria das universidades africanas (especialmente as de língua portuguesa) pouco produzam em termos de novos conhecimentos, limitando-se a 
reproduzir o saber de matriz ocidental. Podemos vislumbrar uma tendência clara, mais acentuada nos países do hemisfério sul, mas presente também em algumas realidades ocidentais, acerca do ensino superior, que responde perfeitamente à tendência da periferização global de que falava anteriormente: uma tendência de reduzir a capacidade de fazer pesquisa e produzir saber por parte da academia, sobretudo o saber não orientado por lógicas de mercado e por encomendas. Isso acontece mediante processos bastante simples, tais como o corte constante em termos financeiros (assumindo várias denominações, por vezes aliciantes), o que deixa pouco espaço aos processos de investigação, reduzindo cada vez mais as universidades a liceus melhorados, com uma parte didática preponderante e, muitas vezes, repetitiva, devido à falta de diálogo com a investigação e a extensão. Hoje, cerca de um estudante a cada três frequenta universidades privadas, totalizando um número de quase 57 milhões de indivíduos. No Brasil, cerca de $72 \%$ dos estudantes universitários estuda em instituições privadas, ao passo que na Europa esta percentagem não chega a $15 \%$ do total. Sem querer demonizar as universidades privadas, estes dados dizem que o compromisso dos governos, sobretudo dos países do hemisfério Sul, para com o ensino público é cada vez mais fraco e a única saída, para muitos, é aderir às propostas das universidades privadas onde, na maioria dos casos, a pesquisa representa um aspeto marginal da missão acadêmica. O mesmo vale no setor da saúde, cujo desmantelamento - na ótica de serviço público - também resulta evidente ao nível internacional. Em consequência, a produção de saber tende a concentrar-se cada vez mais nas universidades públicas, localizadas, em larga medida, no hemisfério norte do planeta, reproduzindo uma divisão internacional do trabalho que muitos dos teóricos da dependência tinham assinalado já nos anos 1960-1970, e que a crítica pós-colonial atualizou.

JBS: Voltando a Moçambique, pode situar o público leitor em relação às principais organizações políticas no contexto moçambicano, a saber: Frente de Libertação em Moçambique (FRELIMO) e Resistência Nacional Moçambicana (RENAMO)? 
LB: A FRELIMO é o partido que sempre governou em Moçambique desde a obtenção da independência, em 1975. Passou por uma experiência de República Popular (ou seja, adesão ao marxismo-leninismo) que não deu certo por motivos exógenos e endógenos, que aqui seria demasiado complexo explicar, sofreu uma guerra civil (que muitos chamam de "desestabilização"), que durou cerca de 16 anos, culminando com a adesão às medidas de ajustamento estrutural (1986-1987), a aprovação de uma nova Constituição liberal (1990) e a assinatura dos Acordos Gerais de Paz em Roma (1992), que permitiram a realização das primeiras eleições multipartidárias da história do país (1994). Hoje, a FRELIMO, embora pertencendo à internacional socialista, é um partido ideologicamente indefinido. Aliás, é um partido que promoveu um processo de privatização (muito mais do que de liberalização) selvagem, cujos membros representam a elite não só política, mas econômica do país, graças ao envolvimento em esquemas ilícitos de vária natureza, que culminaram com o escândalo das ditas “dívidas ocultas”, em que o segundo governo, Guebuza, acendeu empréstimos por 2,2 mil milhões de dólares americanos, para supostamente promover a defesa da costa moçambicana, mas na realidade para fins de enriquecimento pessoal. Uma boa parte desse pessoal se encontra neste momento preso ou sob julgamento em vários cantos do mundo (Estados Unidos, África do Sul, Moçambique), tão que os doadores ocidentais interromperam a ajuda direta ao orçamento do Estado, através do Budget Support, que garantia quase a metade das necessidades financeiras do país, deixando Moçambique numa situação de crise econômica extremamente grave. Apesar disso, a FRELIMO não quer deixar o poder, e as últimas eleições gerais, de 15 de Outubro de 2019, foram caraterizadas por fraudes enormes, que a comunidade internacional, talvez pela primeira vez, reconheceu publicamente. Do outro lado, a RENAMO surgiu em contraposição à FRELIMO socialista, com o apoio do regime rodesiano, de Ian Smith, e, depois, do apartheid sul-africano, mas depois se "nacionalizou", no sentido de que iniciou a ter uma base eleitoral significativa, sobretudo no centro e no norte do país. Hoje, a RENAMO é um partido também pouco definido ideologicamente, que tem se livrado dos apoios incômodos da pior direita internacional, e que se propõe como formação política que pretende estabelecer um regime democrático mais justo e transparente, a partir da realização de eleições não fraudulentas. Depois do terceiro acordo de Paz, assinado este ano (2019) pouco antes das 
eleições, a RENAMO sofreu uma grave cisão, com a sua ala militar que não aceitou as cláusulas do Acordo, se constituindo em Junta Militar, chefiada pelo General Nhongo, cujos objetivos são a destituição do atual líder, Ossufo Momade, e a assinatura de novos acordos de paz com o governo. Esta Junta Militar retomou o antigo método de luta típico da guerra dos 16 anos, ou seja, a guerrilha no Centro do país, assaltando carros e ônibus e bloqueando, na prática, algumas das artérias principais de comunicação no eixo norte-sul. Finalmente, o Movimento Democrático de Moçambique (MDM) é o terceiro partido de Moçambique, com assentos parlamentares, que surgiu em 2009 depois de uma cisão da RENAMO, cujo líder é Daviz Simango (filho do antigo vice-presidente da FRELIMO de Eduardo Mondlane, Ura Simango), com uma concentração de votos sobretudo no Centro do país (Sofala) e em algumas grandes cidades, inclusive na capital Maputo. Entretanto, o cenário político moçambicano pode ser definido de "bipolar" e "bloqueado", pois nenhum partido novo tem tido o poder de quebrar a dupla hegemonia FRELIMO-RENAMO, que continuam a representar os eixos fundamentais da política do país. Basta pensar que os acordos de paz de 2019 que antecederam as eleições foram não só assinados, mas também negociados, ao longo de 2-3 anos, exclusivamente pelos dois maiores partidos moçambicanos (aliás, pelos seus dois presidentes), num evidente processo ad excludendum dos outros partidos, assim como das organizações da sociedade civil, que várias vezes tinham manifestado a vontade de serem envolvidas em tais diálogos.

JBS: Que(ais) mudanças, além da conscientização política, é possível comprovar com a presença das vozes alternativas no contexto moçambicano?

LB: Por enquanto as mudanças fogem à atenção da maioria dos observadores. Como referi anteriormente, do meu ponto de vista as mudanças principais têm a ver mais com a dimensão típica dos movimentos sociais - justamente uma conscientização mais madura de alguns estratos da sociedade moçambicana - do que com a esfera política, onde temos uma situação cristalizada. As vozes alternativas relativas aos movimentos sociais representam um mundo em grande evolução, que está desenhando identidades novas, desde a consciência de classe 
embasada na pauta comum da defesa da terra e de todos os direitos em volta dela no meio rural, até a luta contra abusos e corrupção no meio urbano, por exemplo mediante o rap de intervenção social e política de artistas como Azagaia ou André Cardoso. No meio urbano os movimentos sociais existem, mas, na minha opinião, são menos compactos em relação aos de tipo rural e estão tendo resultados menos palpáveis, pelo menos nos últimos anos. Pois, nos advindos do território urbano, falta uma pauta comum e um perigo imediato de perda de um bem precioso como a terra. Quanto as lutas de tais movimentos podem ter impacto no rumo geral do país é difícil dizer, o que é certo é que os processos de periferização global, em Moçambique, terão de considerar cada vez mais o protagonismo de movimentos sociais e organizações da sociedade civil como atores importantes e pujantes, já não resignados a sofrer os abusos que investidores internacionais e elites políticas locais perpetraram há muito tempo. E este é um resultado notável. Se, depois, pelo menos uma parte dos intelectuais moçambicanos se posicionasse de forma explícita em favor de tais movimentos sociais e das suas instâncias, isso também representaria um momento ímpar na redefinição epistêmica do saber em Moçambique. Só para dar um exemplo, num recente livro sobre justiça em Moçambique, organizado pelo Severino Ngoenha, lancei uma reflexão em volta de um tabu, o da terra pública. Em Moçambique a terra pertence ao Estado, entretanto a elite política local sempre usou este instrumento para se apoderar desta terra e geri-la à maneira que mais lhe convinha. Assim, a terra, mais do que pública, é do Estado e de quem a gere a este nível. Uma diferença relevante, quer em termos conceituais, quer em termos práticos, que - fora do pendor ideológico que tem acompanhado esta questão - mereceria um aprofundamento por parte da academia moçambicana.

JBS: Nos discursos que você tem proferido há uma constante referência ao cenário de (re)existência em Moçambique, como é ser cientista social, pesquisador com nacionalidade moçambicana e crítico político discutindo movimentos sociais alternativos num continente que tem nos seus marcos históricos a discriminação, a desigualdade e a pobreza? 
LB: O cientista social em Moçambique, assim como em muitas outras realidades africanas, deve saber se posicionar. Existem dezenas ou até centenas de intelectuais "orgânicos" ao regime. Nada de mal em apoiar um certo partido ou simpatizar pelo governo do dia. Entretanto, a função de qualquer cientista social é a crítica, mesmo estando (ideologicamente) do lado das forças que apoiam o país. Crítica e produção de novo saber. Vou dar um exemplo: como homem de esquerda, achei a experiência do Lula no Brasil extremamente importante ao nível internacional; entretanto, não sei explicar como é que um governo, com esta caraterização política, conseguiu levar adiante um programa como o Pro-Savana, que estava contra os interesses do bloco social que o Lula defende no Brasil, o dos camponeses e dos pequenos agricultores. Muitos intelectuais moçambicanos não conseguem fazer isso: diferenciar simpatia política com a sua função crítica. O exemplo mais evidente foi a descoberta do G40, um grupo de 40 influencers que na mídia, de forma disfarçada, apoiavam (durante o governo de Guebuza) as ações do executivo. Os jornais públicos, tais como o Notícias, o Domingo e outros representam um país que não existe, apesar do fato de alguns dos jornalistas mais competentes do país trabalharem ali (vários deles foram meus estudantes ou colegas). Num país como Moçambique, o cientista social deve conseguir levar a cabo as suas análises, embora sabendo usar o tom apropriado para aquele contexto específico, consciente da linguagem, dos significados simbólicos das suas palavras e até dos perigos que corre ao se expressar, pois atua num contexto de liberdade muito limitada. Não é novidade que colegas e jornalistas foram gravemente feridos ou até mortos, como no caso do jurista franco-moçambicano Cistac, devido, provavelmente, ao seu posicionamento político, contrário ao governo do dia. Se trata, portanto, de um jogo de cintura muito difícil, entre a necessidade de cumprir com a função social do cientista e o conhecimento do contex to em que este atua.

JBS: Como as vozes dos oprimidos, dos subalternos e dos excluídos podem constituir -se em referenciais para as políticas públicas e sociais? 
LB: Neste momento uma tal perspectiva me parece extremamente improvável, pois tais movimentos, mais ou menos organizados, são classificados como sendo contrários ao regime, até inimigos do Estado. $\mathrm{O}$ mesmo acontece com aqueles intelectuais que manifestam críticas abertas ao Executivo; a reação deste último não é de ouvi-los, mas sim de apertar o controle deles, fechando os espaços públicos onde estes se poderiam expressar. Quanto aos movimentos sociais, ainda mais os que atuam no meio rural, estes defendem interesses reais e legítimos, mas que não encontram eco no panorama político, nem nos partidos da oposição ou na mídia nacional. Tais vozes, porém, estão conseguindo ganhar batalhas significativas, travando ou desacelerando - como anteriormente explicado - processos econômicos de grande vulto, tais como o Pro-Savana ou a silvicultura no centro do país. Mas se trata de lutas travadas contra dois inimigos constantes: multinacionais estrangeiras e instituições moçambicanas, a todos os níveis, desde o governo central até o distrital. O que falta hoje, me parece, é uma ligação entre estas lutas e a dimensão política dos partidos, os quais não estão percebendo as mudanças que estes movimentos estão trazendo para Moçambique, continuando em suas disputas fechadas e, em larga medida, fora do tempo. É por causa de um tal desfasamento que a sociedade moçambicana está ficando fixada na eterna guerra FRELIMO-RENAMO, enquanto as dinâmicas sociais e econômicas estão desenhando realidades cada vez mais complexas e ligadas aos novos cenários globais, que valeria a pena estudar e compreender, além das pertenças ou simpatias ideológicas ou políticas deste ou daquele investigador.

JBS: Apesar dos avanços identificados nos paradigmas dominantes, ainda constitui-se como permanente, entre outros, o lugar de fala e a produção autoral dos sujeitos invisibilizados socialmente. Como reverter esse quadro, superando o aprisionamento do cânone ocidental que reproduz, dentro dos seus domínios de pensamento e prática, a colonialidade do poder nas produções científicas?

LB: Este é outro problema premente, na realidade africana e moçambicana. A colonialidade ainda domina a pouca produção intelectual que vem da África, aliás, o fato de haver escassa 
produtividade intelectual já representa um sinal inequívoco de que esta primazia continua. Vou dar mais um exemplo, para o leitor perceber melhor. Quando ensinava no Departamento de Filosofia de uma universidade privada em Moçambique, não havia monografia que não abordasse Platão, Aristóteles, Locke ou Rousseau. Grandes filósofos, sem dúvidas, mas será que não havia espaço para o pensamento africano ou, no geral, das epistemologias do Sul? Pode parecer incrível, mas fui eu que introduzi, nesta universidade, o Afrocentrismo de Asante, passando por Anta Diop, Martin Bernal e todos os outros. O que não significa aderir de forma acrítica a estas teorias, mas dar a possibilidade aos jovens filósofos moçambicanos de conhecer uma outra perspectiva, diferente do episteme ocidental. Tenho muito orgulho de que um desses jovens, Ergimino Mucale, tenha na altura defendido uma monografia sobre o Afrocentrismo em Asante, que depois se transformou num livro, tornando-se como uma das referências moçambicanas deste tipo de corrente.

JBS: O que um Italiano erradicado na África teria para dizer sobre os movimentos sociais ao público leitor da Revista Debates Insubmissos, pensando nas lições deixadas pela passagem ao Brasil?

LB: Eu diria o seguinte: assim como existe um prejuízo negativo para com África, muito difuso até hoje em todo o mundo, no Brasil me deparei com um prejuízo positivo. O que é muito bom, em termos de abordagem e de abertura mental; mas isso também pode atrapalhar as análises sociológicas e filosóficas. As categorias, por exemplo, relativas à dimensão política que a gente usa no Ocidente (a partir da mais clássica, esquerda/direita) são de uso muito complicado em África; assim como não é possível pensar ao continente africano como uma vítima global do neoliberalismo. Mesmo em África há vítimas (a maioria da população) e beneficiados da periferização global, e as análises dos cientistas sociais devem saber distinguir tais dinâmicas, e trazê-las a tona. Os movimentos sociais africanos também seguem pautas diferentes, em larga medida, dos movimentos (geralmente urbanos) do Ocidente, mas não muito distantes dos movimentos sociais rurais de Brasil e do resto da América Latina. Para compreender tais 
movimentos é necessário um árduo trabalho empírico, fora de qualquer convicção ideológica e política, buscando as suas caraterizações essenciais, seus modos de atuação e seus saberes, abordando-os com a disposição de querer aprender e ouvir, mesmo que este aprendizado nos decepcione em alguns aspectos. Esta, acho eu, seria a maior contribuição que um cientista social com um claro posicionamento em relação aos processos de periferização global poderia trazer à reflexão internacional sobre os movimentos sociais em África.

\section{REFERÊNCIAS}

BUSSOTTI, Luca. Terra do Estado não é terra pública: formas de usurpação da terra em Moçambique. In NGOENHA, Severino. (In)Justiça: Terceiro Grande Consenso Moçambicano. Maputo: Real Design, 2019, pp. 99-113

ELLIS, Stephean; KESSEL, Ineken van (Orgs.). Movers and shakers social movements in Africa. Leiden; Boston: Brill, 2009.

MAMDANI, Mahmood (Org.). African studies in social movements and democracy,

Dakar: Codesria, 1995.

MELUCCI, Alberto. Getting involved: identity and mobilization in social movements.

Research International Social Movements, v. 1, 1988.

MUCALE, Ergimino Pedro. Afrocentricidade: complexidade e liberdade, Moçambique: Paulinas, 2013.

NGOENHA, Severino Elias. Lomuko. Maputo: Publifix, 2019.

NGOENHA, Severino Elias. Os tempos da filosofia: filosofia e democracia moçambicana. Maputo: Imprensa Universitária, 2004.

SANTOS, Boaventura de Sousa \& MENESES, Maria Paula (Orgs.). Epistemologias do Sul. São Paulo. Editora Cortez, 2010.

Submetido em: $30 / 12 / 2019$

Aprovado em: 04/01/2020 